\title{
EDITORIAL
}

\section{SRI LANKAN BIOTA AS AN ECONOMICALLY VIABLE NATURAL RESOURCE}

The historical use of plants in the treatment of ailments resulted in several organized systems of traditional medicine. The therapeutic properties of a large number of plants were recognized and documented in Materia Medica and Olaleaf manuscripts. These form the basis of much of Sri Lanka's traditional systems of medicine. Today, about $40-50 \%$ of currently used drugs which come under the allopathic system of treatment are natural products-based compounds. However, it is estimated that only $2 \%$ of the approximately 250,000 flowering plants in the world have been thoroughly evaluated as new sources of drugs. Therefore, efforts at mapping of medicinal potential of the earth's plants, animals and microorganisms are urgently needed, because the unchecked habitat destruction results in the extinction of species. The latter issue should be of great importance to politicians and policy makers.

The main diseases of this century are AIDS, malaria, tuberculosis and other infectious diseases, cancers, heart disease, central nervous system disorders, including Alzheimer's disease. Apart from drugs concerned with human health other important areas of research include discovery of safe new agents for crop protection and veterinary medicines. Coupled to such programmes, it is important to carry out biodiversity inventories and surveys, examine and preserve traditional medicine practices and formulate long-term strategies to ensure sustainable harvesting.

The World Conservation Monitoring Center has designated Sri Lanka as a "hotspot" in terms of biodiversity. The indigenous flora of Sri Lanka comprise of about 7,500 plant species. Of the 3360 flowering plants about 830 (25\%) species are endemic to the island. In the Sinharaja forest $\left(120 \mathrm{~km}^{2}\right)$ in the low country wet zone, some families such as Dipterocarpaceae show 100\% endemism. Other families which include high endemism are Anacardiaceae, Dilleniaceae, Melastomataceae, Myrtaceae, Orchidaceae and
Rubiaceae. Of the 211 woody trees and lianas found in the Sinharaja forest, 66\% (about 139 species) are endemic. Although Dipterocarps are widely distributed in the Far East, their ancestors are found in the hills of Sri Lanka. The nonendemics on the other hand, are more accessible (due to abundance and the relatively small area of the island) compared to most countries in the South Asian region. Thus, Sri Lanka is a repository of a rich variety of flowering plants, lower plants, reptiles, mammals and amphibians and has the highest diversity per unit area, in the whole of Asia. The therapeutic potential of Sri Lankan endemics remains completely unknown. In general, little emphasis has been placed on the scientific basis of the medicinal properties of Sri Lankan plants. All these facts point to the urgent need to investigate the biota of Sri Lanka with a view to identify, protect and commercially harness such knowledge, an activity often referred to as biochemical prospecting.

Among the main impediments to such research is the lack of good bioactivity testing facilities in Sri Lanka. Such facilities require high investment and even when an active compound is discovered it may only serve as a lead compound for the synthesis of a related and more useful compound. Therefore, lack of good facilities for chemical synthesis is another impediment to bioprospecting. Also, research into our biota requires a large pool of scientists working in these efforts. Examples of relevant areas where trained personnel are lacking include systematics, ethnobiology, ethnomedicine, chemistry, cell biology, biotechnology or production methods and quality control in pharmaceutical development. Unfortunately, due to various reasons ranging from poor scientific infrastructure and employment opportunities to poor remuneration has resulted in a systematic brain drain of our qualified scientists to the developed world. All of the above impediments are symptomatic of chronic under-funding of scientific research in Sri Lanka since independence. 
Collaboration with foreign institutes offers a way out of this problem. Countries and regions such as Panama, Madagascar, Vietnam and Laos, Papua New Guinea, Central Asia, Costa Rica, Philippines, Jordan, Jamaica, West Africa and Latin America have begun bioprospecting efforts mainly through collaboration with the International Cooperative Biodiversity Groups (ICBG), USA, in a unique effort that addresses the interdependent issues of drug discovery, biodiversity conservation, and sustainable economic growth. Funding for this program has been provided by six components of the National Institutes of Health (NIH), the Biological Sciences Directorate of the National Science Foundation (NSF) and the Foreign Agriculture Service of the USDA.

However, in Sri Lanka the guidelines for entering into useful collaborations with foreign institutes and scientists have not been comprehensively formulated. Lack of such guidelines in biochemical prospecting often leads to confrontation between the scientists involved in development efforts and the environmental groups. The latter tend to be suspicious of local scientists, labeling them as exporters of the country's resources for profit, and xenophobic of their foreign collaborators. The idea that biodiversity protection and biochemical prospecting are indeed two sides of the same coin came to the forefront after Merck signed a contract with Costa Rica's Instituto National de Biodiversidad in 1991, announcing advance compensation for biological samples and a share of royalties derived from any new products in the joint venture. This agreement could serve as a model for Sri Lanka.

\section{Veranja Karunaratne}

